\title{
PERSPECTIVES
}

\section{The COVID-19 lockdowns: a window into the Earth System}

Noah S. Diffenbaugh (D, Christopher B. Field (D), Eric A. Appel(D), Ines L. Azevedo, Dennis D. Baldocchi, Marshall Burke (1), Jennifer A. Burney (1), Philippe Ciais (D), Steven J. Davis (1), Arlene M. Fiore ${ }^{0}$, Sarah M. Fletcher, Thomas W. Hertel, Daniel E. Horton, Solomon M. Hsiang (D), Robert B. Jackson (1), Xiaomeng Jin (1), Margaret Levi, David B. Lobell(D, Galen A. McKinley (D), Frances C. Moore, Anastasia Montgomery, Kari C. Nadeau (D), Diane E. Pataki, James T. Randerson (D), Markus Reichstein, Jordan L. Schnell(1), Sonia I. Seneviratne (D), Deepti Singh, Allison L. Steiner and Gabrielle Wong-Parodi(i)

Abstract | Restrictions to reduce human interaction have helped to avoid greater suffering and death from the COVID-19 pandemic, but have also created socioeconomic hardship. This disruption is unprecedented in the modern era of global observing networks, pervasive sensing and large-scale tracking of human mobility and behaviour, creating a unique test bed for understanding the Earth System. In this Perspective, we hypothesize the immediate and long-term Earth System responses to COVID-19 along two multidisciplinary cascades: energy, emissions, climate and air quality; and poverty, globalization, food and biodiversity. While short-term impacts are dominated by direct effects arising from reduced human activity, longer-lasting impacts are likely to result from cascading effects of the economic recession on global poverty, green investment and human behaviour. These impacts offer the opportunity for novel insight, particularly with the careful deployment of targeted data collection, coordinated model experiments and solution-oriented randomized controlled trials, during and after the pandemic.

COVID-19 is disrupting lives and livelihoods around the world. The most important consequences are the public health crisis and associated economic and humanitarian disasters, which are having historic impacts on human well-being. In addition, after more than four months of widespread sheltering and other restrictions, it is clear that the scale and persistence of socioeconomic disruption represent an unprecedented modification of human interactions with the Earth System, the impacts of which will be long-lasting, widespread and varying across space and time (FIG. 1).

Some obvious and immediate effects are reflected in the worldwide reports of reduced traffic congestion, clearer skies, cleaner waterways and the emergence of wildlife into human settlements. In addition to anecdotal reports, effects are being detected in a variety of long-term physical observations (from improved air quality to reduced seismic noise) and socioeconomic indicators (such as reduced mobility and declining economic growth and greenhouse-gas emissions). While some of these impacts might be considered beneficial to the environment, negative consequences are also emerging, including cascading effects for poverty, food security, mental health, disaster preparedness and biodiversity.

As with previous calamities, such as volcanic eruptions ${ }^{1-3}$, electrical blackouts ${ }^{4}$ and the short-term reductions in human mobility following the 11 September attacks ${ }^{5}$, the current COVID-19 crisis will inevitably present a new test bed for understanding how the Earth System works, including the critical role of humans ${ }^{6}$. This test bed could provide answers to long-standing questions, such as the processes linking heterogeneous local pollutant emissions and regional atmospheric chemistry and air quality, or the relationship between global economic integration and poverty-driven environmental degradation. The uniquely pervasive disruption also has the potential to reveal novel questions about the Earth System that have not previously been asked, and many diverse efforts are already underway to learn from this inadvertent Earth System modulation.

In this Perspective, we examine the impacts of COVID-19-related social disruption on two multidisciplinary pathways: energy, emissions, climate and air quality; and poverty, globalization, food and biodiversity. We first consider hypotheses about how the COVID-19 disruption could influence the Earth System along these pathways and then explore the potential for rapid advances in understanding if we are able to carefully observe, test and characterize Earth System processes during and after the COVID-19 event.

\section{COVID-19 disrupts the Earth System}

Under usual daily life, the human footprint on the Earth System is vast. As a result, a very large perturbation is required to cause an observable difference from this 'business-as-usual' baseline: COVID-19 is providing that perturbation. As of July 2020, as much as half the world's population has been under some version of sheltering orders ${ }^{7}$ (FIC. 2a). These orders have substantially reduced human mobility and economic activity (FIG. 2b), with $~ 70 \%$ of the global workforce living in countries that have required closures for all non-essential workplaces and $~ 90 \%$ living in countries with at least some required workplace closures $^{8}$.

The scale of this socioeconomic disruption is likely to be detected in the Earth System at local to global scales (FIG. 1). Some responses are direct, while others will result from interactions between humans, ecosystems and climate. The impacts of the socioeconomic disruption are, thus, also likely to vary across timescales: although the direct impacts of the reduction in human mobility will be strongest during the sheltering period, many of the most lasting impacts could result from cascading effects 


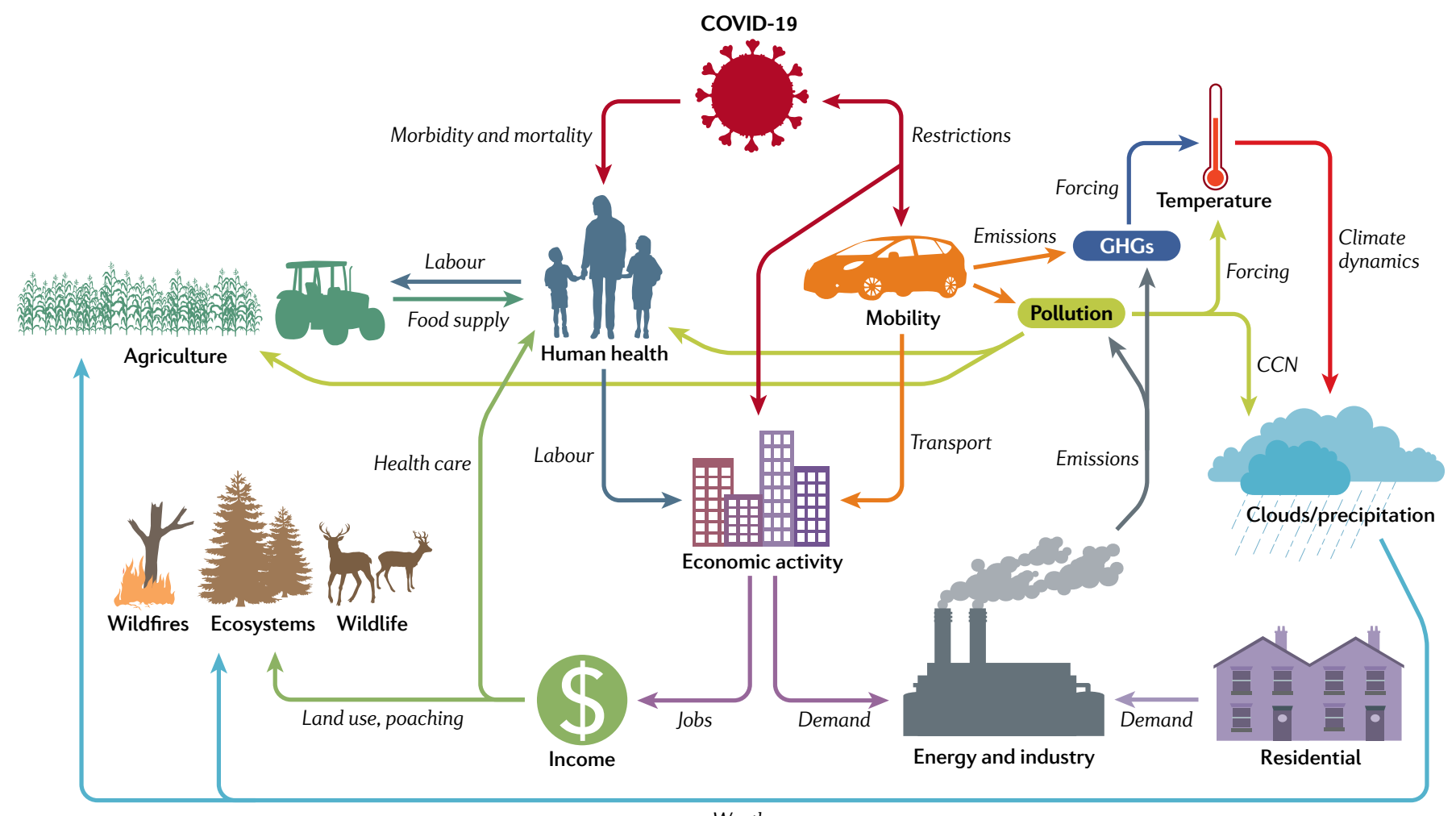

Weather

Fig. 1 | Earth System interactions linked to the COVID-19 socioeconomic disruption. Two pathways highlight the potential for multi-dimensional Earth System responses: energy, emissions, climate and air quality; and poverty, globalization, food and biodiversity. Interactions will manifest differently in different regions and on different timescales, with the sign of the interaction potentially changing across different phases of the event. Note that these interactions are indicative of primary hypotheses, but not all possible interactions are shown. CCN, cloud condensation nuclei; GHGs, greenhouse gases.

initiated by the economic recession, some of which (such as those induced by changes in public policy, the structure of the economy and/or human behaviour) could persist for decades following the initial economic recovery.

The reduction of human activities, and the efforts to manage their revival, have varied around the world (FIG. 2). Given the variations in the timing, strength and approach to sheltering ${ }^{7}$, it may be possible to track effects through the components of the Earth System. Likewise, because the large-scale reduction in human activity will necessarily be temporary, it will be possible to observe whether or how Earth System processes return to their previous states after activity returns to something approaching pre-pandemic levels. The event, therefore, provides a unique test bed for probing hypotheses about Earth System sensitivities, feedbacks, boundaries and cascades ${ }^{6,9-11}$, presuming that the observing systems are in place to capture these responses (BOX 1).

Path I: Energy, emissions, climate and air quality. Impacts on energy consumption, and associated emissions of greenhouse gases and air pollutants, are likely to cascade across timescales (FIG. 1). In the near-term, reductions in mobility and economic activity have reduced energy use in the commercial, industrial and transportation sectors, and might have increased energy use in the residential sector ${ }^{12,13}$. These direct impacts will interact with secondary influences from energy markets, such as the severe short-term drop in oil prices in March and April 2020 (REF. ${ }^{14}$ ). Further, as with past economic recessions ${ }^{15,16}$, energy demands and the mix of energy sources - are likely to evolve over the course of the economic recovery in response to market forces, public preferences and policy interventions ${ }^{17,18}$. This evolution could have long-term effects on the trajectory of decarbonization if, for example, the economic disruption delays the implementation of ambitious climate policy or results in decreased investments in low-carbon energy systems ${ }^{16}$. Alternatively, large government stimulus spending could target green investments that overhaul outdated infrastructure and accelerate decarbonization ${ }^{18}$.

Misunderstandings have arisen with regards to declines in carbon dioxide emissions caused by COVID-19-related disruption, with some interpreting short-term reductions to suggest that austerity of energy consumption could be sufficient to curb the pace of global warming. A reduction in fossil $\mathrm{CO}_{2}$ emissions proportional to the economic decline ${ }^{15}$ would be dramatic relative to previous declines. For example, the decline in daily $\mathrm{CO}_{2}$ emissions peaked at $>20 \%$ in the largest economies during the period of sheltering ${ }^{13}$ (FIG. 2C) and the cumulative reduction in global emissions was $\sim 7 \%$ from January through April 2020 (REF.'2) (FIG. 2d). However, these daily-scale declines are temporary ${ }^{13}$ and the rebound in emissions that is already evident ${ }^{13,19}$ (FIG. 2c) supports the likelihood of a reduction in annual emissions that is smaller than $7 \%$.

Nevertheless, a 5\% drop in annual fossil $\mathrm{CO}_{2}$ emissions from 37 billion metric tonnes per year ${ }^{20}$ would exceed any decline since the end of World War II (REF. $\left.{ }^{13}\right)$. There is a strong basis that such a reduced atmospheric $\mathrm{CO}_{2}$ growth rate would lead to a reduced ocean carbon $\operatorname{sink}^{21}$ and, thus, also a temporary reduction in the rate of ocean acidification. On the other hand, a 5\% decrease would still leave annual 2020 emissions at $\sim 35$ billion metric tonnes, comparable to emissions in $2013\left(\right.$ REF. $\left.^{20}\right)$. Such a decline - and associated changes in the ocean and land carbon sinks - might not be statistically detectable above the year-to-year variations 
in the natural carbon cycle and, regardless, global atmospheric $\mathrm{CO}_{2}$ concentrations will inevitably rise in 2020, continuing a long-term trend. Progress in understanding the carbon-cycle responses to COVID-19 will, therefore, be challenging and, at a minimum, will require new methods for tracking the unprecedented short-term perturbation in emissions through the Earth System.

Based on past events and fundamental understanding, there are a number of hypotheses of how sheltering-induced changes in atmospheric emissions could influence the climate system more broadly
(FIG. 1). On short timescales, reduced air travel decreases the abundance of contrails, which can be detected in the radiation budget (as occurred during the brief cessation of air travel following the 11 September attacks ${ }^{5}$ ). The response of atmospheric aerosols to sheltering is likely to vary regionally, with changes in emissions, meteorology and atmospheric chemistry influencing the outcome (BOX 2). While reductions in aerosols have occurred in many locations (FIG. 3), they have also been observed to increase in others ${ }^{22}$, highlighting the important role of secondary chemistry in these assessments. Changes in atmospheric aerosols could further influence cloud and precipitation processes ${ }^{23,24}$, and might be detectable in the local surface energy budget ${ }^{25}$. A reduction in scattering aerosols will also cause warmer surface temperatures over emitting regions ${ }^{26}$ (FIG. 4), potentially manifesting as more frequent and/or intense heatwaves ${ }^{27,28}$. If aerosol reductions persist across the Northern Hemisphere, this could have short-term impacts on the onset, intensity and/or intraseasonal variability of monsoon rainfall ${ }^{29-31}$, particularly given that both local and remote aerosol emissions can influence variability within the monsoon season ${ }^{31}$.

a Timing of sheltering intensity

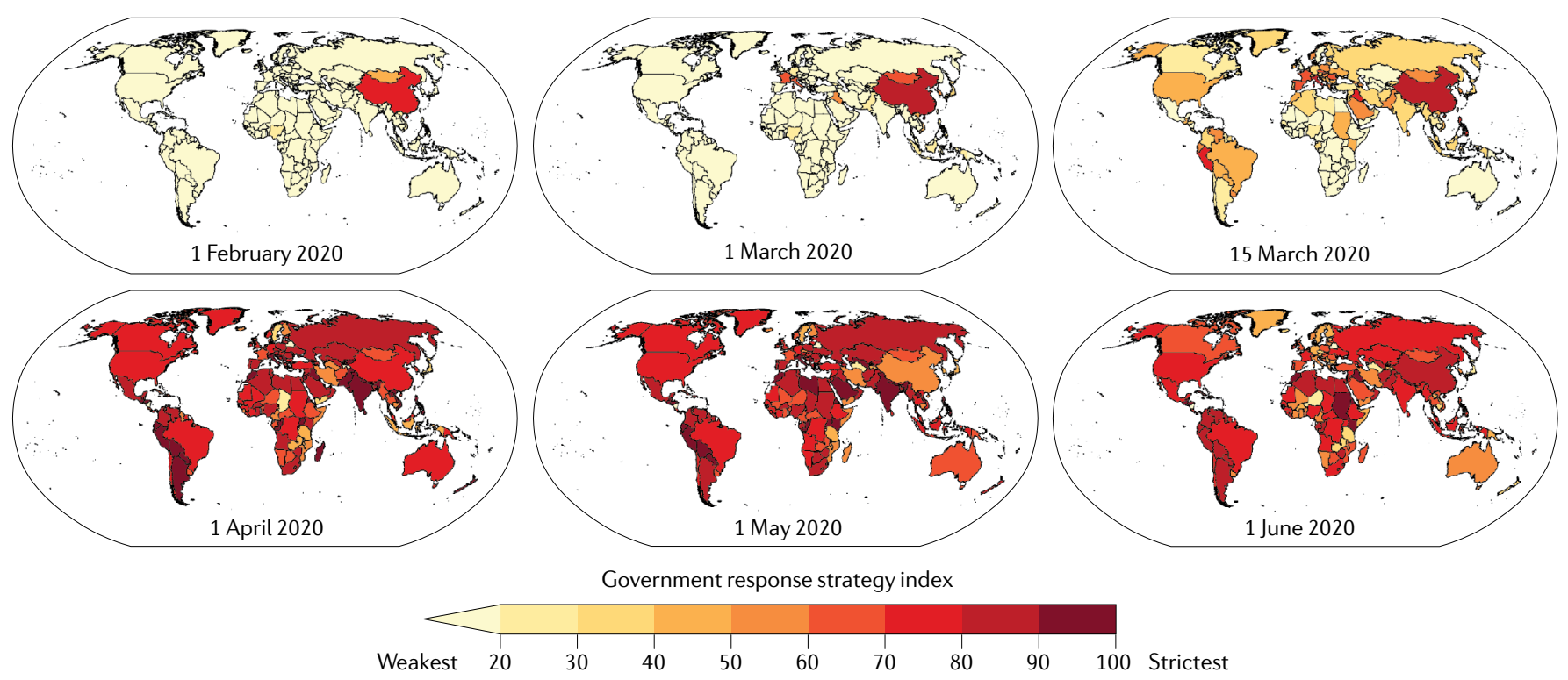

b Sheltering intensity

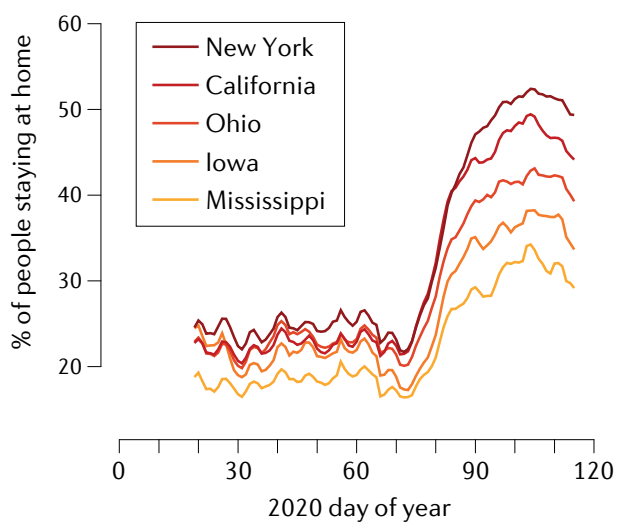

C Daily $\mathrm{CO}_{2}$ emissions

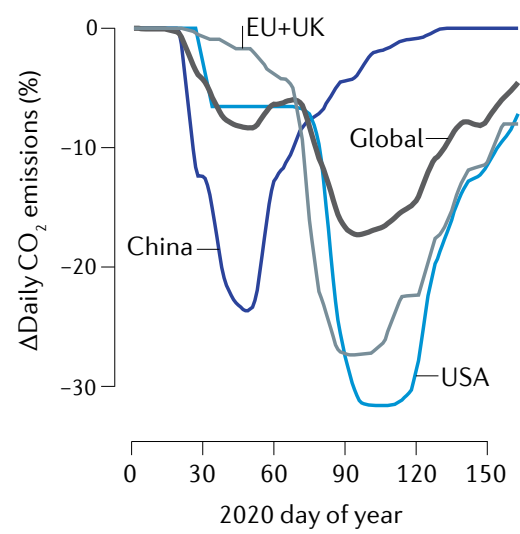

d Cumulative $\mathrm{CO}_{2}$ emissions

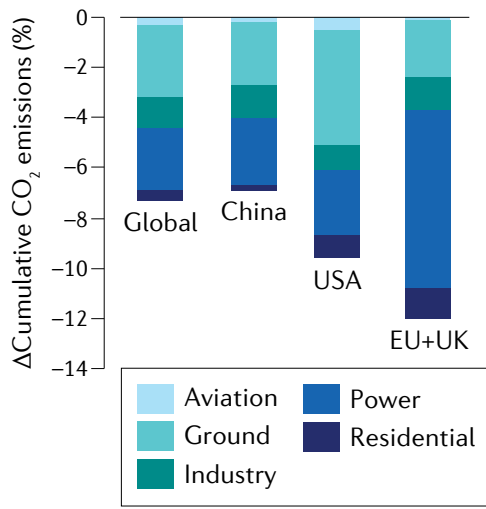

Fig. 2 Sheltering orders and changes in mobility and $\mathrm{CO}_{2}$ emissions. a | The Oxford Government Response Stringency Index ${ }^{7}$ on six different dates between 1 February and 1 June. $\mathbf{b} \mid$ Percentage of people staying at home, as estimated by mobility data from cell phones ${ }^{91}$, for five US states. c| Percentage change in carbon dioxide emissions ${ }^{13,92}$ for the World, China, the USA and Europe. Each day's value is the percentage departure in 2020 from the respective day-of-year emissions in 2019, accounting for seasonality. d | Percentage change in cumulative carbon dioxide emissions ${ }^{12,93}$ for January through April 2020 compared with January through April 2019 for the World, China, the USA and Europe. The differences in timing of sheltering and mobility in different areas of the world are a source of information that can be used in understanding causality in the Earth System response. In the case of carbon dioxide emissions, the early onset and subsequent relaxation of sheltering in China is clearly reflected in the timing of reduction and subsequent recovery of emissions in China relative to the USA and Europe. 


\section{Box 1 | Datasets for understanding the Earth System impacts of COVID-19 disruption}

A wide range of data could be leveraged to understand Earth System changes during the COVID-19 pandemic. These include long-term, operationally deployed Earth observations from satellite remote-sensing platforms and atmospheric, oceanic and surface measurement networks. Although long-term socioeconomic data are also operationally available, a 1-2-year processing lag can inhibit real-time analysis. Access to long-term private-sector data could remove some of these barriers. A range of shorter-term and/or intermittent observations are also available. These include stationary and mobile measurements of the atmosphere, ocean and near-surface environment, as well as energy, trade, transportation and other socioeconomic data available at either fine resolution for short periods or coarse resolution for longer periods.

One of the most potent opportunities will be to safely deploy observations in geographic areas or economic sectors where there is already a rich pre-existing data baseline; where Earth System models have generated specific, testable hypotheses; or where initial observations suggest that a strong or unexpected response is already emerging. This strategy could include deployment of stationary and/or mobile sensors, short-term online or phone surveys, and 'citizen-science' opportunities via crowd-sourcing platforms such as the USA National Phenology Network, iNaturalist, PurpleAir and Smoke Sense. There are also abundant opportunities to leverage newer, emerging datasets - such as from cell-phone GPS, social media, e-commerce and the private satellite industry - that, if handled with care to preserve privacy, could help to bridge the gaps in long-term, operational data.

Despite the prevalence of extensive datasets, the current COVID-19 crisis is revealing limitations in the ability to measure critical variables in real time. For example, the event has made clear that the world is ill-equipped to make real-time measurements of economic activity and its immediate consequences. It is also revealing deficiencies in real-time-measurement capacity for emissions of some air pollutants and greenhouse gases, as well as highlighting longer-known issues like a relative inability to assess the vertical structure of pollution in the atmosphere. The crisis is demonstrating the urgent need for improved data, models and analysis to understand and correct those deficiencies.

Many sectors would benefit from a public repository containing the heterogeneous data that are critical to fully understand this unique planetary-scale disruption. Some data sources are public, some are proprietary and some do not yet exist. As has been proven repeatedly in recent years, an open, public repository providing all of these heterogeneous data in a uniform, coordinated format would enable novel, unpredictable insights across multiple research disciplines, long after the event has passed.

On longer timescales, changes in the energy intensity of the economy, the carbon intensity of energy or the pace of deforestation could affect the long-term trajectory of global climate (through the trajectory of greenhouse gas emissions and associated land and ocean carbon-cycle feedbacks). These effects could go in either direction: for example, in the US electricity sector, coal plants will likely shut down at an accelerated pace as a result of the economic slowdown, continuing a long-term decline $^{32}$. However, in the transportation sector, policy intervention to stimulate the economy might loosen emissions standards $^{33}$, increasing emissions relative to the pre-pandemic trajectory.

The short-term reductions in pollutant emissions have already resulted in noticeable changes in air quality in some regions (BOX 2). If sustained, improved air quality could yield multiple benefits. These include improved crop health ${ }^{34}$, as air pollution can reduce regional harvests by as much as $30 \%$ $\left(\right.$ REF. $\left.^{35}\right)$. In addition, ambient air pollution is a significant cause of premature death and disease worldwide ${ }^{36}$, even from short-term exposure $^{37,38}$. Several well-documented historical examples illustrate how decreased ambient air pollution can improve human health $^{39}$. These include effects from short-term reductions in traffic, travel and/or industrial activities associated with events such as the 1996 Atlanta Olympic Games $^{40}$ and 2008 Beijing Olympics ${ }^{41-45}$. While associations between air quality and health outcomes are hypothesized in studies of the current pandemic ${ }^{46,47}$, understanding the role of air quality as an indicator for the epidemic trajectory is an emerging challenge. Further, any health improvements resulting from improved air quality during the pandemic should not be viewed as a 'benefit' of the pandemic but, rather, as an accidental side effect of the sheltering that was imposed to protect public health from the virus.

Some of the most lasting impacts of the COVID-19 crisis on climate and air quality could occur via insights into the calculation of critical policy parameters. Two of the most important, and controversial, are the value of mortality risk reduction (sometimes termed the value of a statistical life, or VSL) and the pure rate of time preference (or PRTP), which is one component of the social discount rate and measures willingness to trade off well-being over time. The VSL is important to the analysis of all environmental regulation in the United States and can determine whether environmental regulations as mundane as a labelling requirement for toxic chemicals will pass a cost-benefit test. The PRTP is important in evaluating long-term societal trade-offs - most notably, climate-change regulation - and can be important in calculating an economic value of avoiding climate damages $^{48,49}$. With a higher PRTP, aggressive mitigation of greenhouse gases becomes less attractive, while a low rate, which places relatively higher value on the well-being of future generations, suggests that far more aggressive regulation of today's emissions is warranted.

Both the VSL and the PRTP can be difficult to quantify. However, the COVID-19 crisis is making these trade-offs more explicit, as governments, communities and individuals make historic decisions that reflect underlying preferences for current and future consumption and the trade-off between different types of economic activity and individual and collective risk. The diverse responses to the unusual conditions during the pandemic could reveal far more about how different societies manage these trade-offs than has been revealed in the last half-century. As those insights are incorporated into the formal policy-making apparatus, they will have lasting effects on the regulations that impact the long-term trajectory of climate and air quality.

\section{Path II: Poverty, globalization, food and} biodiversity. By amplifying underlying inequities in the distribution of resources, the socioeconomic disruption caused by the response to COVID-19 will almost certainly have negative long-term impacts on human health and well-being. In particular, the economic shock is likely to increase the extent and severity of global poverty ${ }^{50}$, both from direct impacts on health, employment and incomes and through disruptions of supply chains and global trade ${ }^{51}$. The severe impacts on poverty rates and food security that are already emerging ${ }^{50}$ are indicative of these disruptions and are a sign of how tightly many of the world's poorest households are now interwoven into the global economy. The unwinding of these relationships in the wake of restrictions on human mobility and associated economic shocks will provide insight into the role of economic integration in supporting livelihoods around the world. A severe and prolonged deepening of global poverty is also likely to reduce available resources for climate mitigation and adaptation, 
increasing climate risks and exacerbating climate-related inequities.

The global agriculture sector is a key sentinel for the response of poverty to the pandemic. Primary near-term questions centre around how food security and agriculture-dependent incomes might be affected by unprecedented shocks to local labour supply and global supply chains. A first-order impact has been the income shock associated with widespread sheltering ${ }^{8}$. Loss of wages in both low-income and high-income countries with limited social safety-nets will drive food insecurity and poverty ${ }^{50}$.

It is possible that agricultural production in rural areas will proceed largely unaffected, particularly for larger producers of field crops that tend to be heavily mechanized. However, in many locations and for many specialty crops, agriculture still relies heavily on field labour; sufficient labour supply during the key planting and harvest periods is crucial, and there are frequently labour shortages at these critical times. How these pre-existing labour-supply challenges are affected by the scale and scope of sheltering remains to be seen. In the USA, meat-packing plants have become hotbeds of COVID-19, raising the question of whether excessive concentration of this industry might have led to a loss of resilience ${ }^{52}$. Sheltering-induced return migration from urban to rural areas, as has been widely reported in India, could alleviate agricultural labour shortages in some developing countries. However, mandated sheltering could cause reductions in plantings, which, in combination with the prospect of sheltering during the harvest season, could reduce subsequent harvests.

Such supply-side shocks could combine with general disruption of global trade ${ }^{53}$ to trigger a cascading series of export bans like those that occurred in 2007-2008 $\left(\mathrm{REF}^{54}{ }^{54}\right.$, which caused a spike in grain prices and contributed to unrest around the world ${ }^{55}$. Initial export restrictions are already emerging ${ }^{56}$. Given that agriculture prices are important for both consumers and producers, such bans tend to hurt rural producers in favour of protecting urban consumers in the exporting countries ${ }^{57}$. They can also lead to food shortages in import-dependent countries and rapid increases in international commodity prices $^{58}$, as well as acting to amplify the impacts of climate variability on poverty ${ }^{59}$. However, global grain stocks are much larger today than they were in 2007, which should help buffer some sheltering-related production shortfalls, should they arise.
Deepening of global poverty is likely to have lasting negative environmental impacts (including deforestation, land degradation, poaching, overfishing and loosening of existing environmental policies), as a larger share of the global population is pushed towards subsistence. For example, after decades of efforts to replace environmental degradation with earnings from ecotourism, the collapse of tourism in the wake of COVID-19 is coinciding with a rapid increase in illegal poaching in southern African parks ${ }^{60}$. The rapid response is a potential indicator of the importance of the large African tourism industry for the preservation of endangered needed to distinguish the contributions of income and governance/enforcement. Likewise, deforestation in the Brazilian Amazon surged to $>2,000 \mathrm{~km}^{2}$ in the first five months of 2020, an increase of $~ 35 \%$ compared to the same period in $2019\left(\mathrm{REF}^{61}\right)$. species. However, further analysis is
Governance appears to be playing a key role in this initial short-term resurgence during the COVID-19 sheltering. Over the longer term, historical drivers ${ }^{62,63}$ suggest that a prolonged poverty shock is likely to increase deforestation and biodiversity loss. These cascading impacts on ecosystems and biodiversity offer a sobering contrast to the reports of wildlife 'rebounds' occurring in response to local sheltering ${ }^{64}$.

Changes in human behaviour and decision-making induced by the pandemic are also likely to cascade through the globalized Earth System over the long term. For example, although sheltering orders are reducing personal vehicle use, the long-term impacts are less clear and will be determined, in part, by how human behaviours respond to the pandemic. If, for instance, the pandemic causes people to feel more dependent on cars as 'safe places', that dependence could act to further reinforce the prominence of the automobile at the

\section{Box 2 | Interpreting energy, emissions, climate and air quality responses}

Changes in atmospheric pollutants have co-occurred with COVID-19 sheltering restrictions ${ }^{22,78,79}$, including broadly publicized reductions in satellite-derived tropospheric $\mathrm{NO}_{2}$ columns $^{95}$ (FIG. 3a). The sheltering period can shed light on processes controlling atmospheric constituents on local to global scales. However, accurate attribution requires careful consideration of emissions, meteorology and atmospheric chemistry.

\section{Anthropogenic forcing}

The large regional variations in pollutant emissions will create spatial heterogeneity in the response of air quality to sheltering. While some regions show decreases in aerosols (FIG. 3b), post-shutdown increases have been observed in urban regions in China due to secondary chemistry ${ }^{22}$. Sheltering measures were implemented during spring/autumn transitions (FIG. 2), when energy demand, usage and fuel mix fluctuate sharply. Further, observed changes in atmospheric constituents might also be influenced by longer-term emission reductions. These factors must be carefully considered when attributing changes to COVID-19 restrictions. The COVID-19 disruption provides impetus to combine existing energy-consumption data with robust ground-based and space-based atmospheric-chemical measurements to characterize local pollutant emissions and the resulting atmospheric chemistry that drives air quality.

\section{Distinguishing signal from noise}

Natural climate variability must be accounted for to quantify the human influence on short-term Earth System changes ${ }^{96-98}$. In the case of quantifying the response of regional air pollution to sheltering, several limitations must be overcome. Irregular sampling frequencies over limited observing periods are a primary barrier. For example, space-based retrievals of air pollutants such as $\mathrm{NO}_{2}$ are sensitive to physical (such as daily boundary-layer variations) and chemical (such as seasonal lifetime variability) processes. In the Northern Hemisphere, peak sheltering has coincided with the period when $\mathrm{NO}_{2}$ lifetimes are transitioning from winter maximum to summer minimum, affecting estimation of emissions differences from satellite column density retrievals (FIG. 3a). Further, as $\mathrm{NO}_{2}$ columns cannot be retrieved under clouds, concentration differences calculated within the period of sheltering, or between 2020 and previous years, could arise due to variable meteorology.

\section{Opportunities for the future}

COVID-19 sheltering could help elucidate Earth System processes along the energy-emissionsclimate-air quality pathway. For example, observations during this period could yield insights into road-traffic contributions to local air quality, as passenger-car emissions decline but trucking emissions persist. Connections between emissions and climate may be revealed from observations in regions with large aerosol forcing signals, offering much-needed tests for local-to-global responses simulated by Earth System models (FIG. 4). For example, asymmetric hemispheric warming is a robust model response to regional reductions in aerosol emissions ${ }^{26}$; can this signal be distinguished from long-term aerosol trends when accounting for internal variability? These queries sample the rich opportunities to advance understanding of processes governing linkages between energy use, emissions, climate and air quality. 
a Tropospheric $\mathrm{NO}_{2}$ column densities
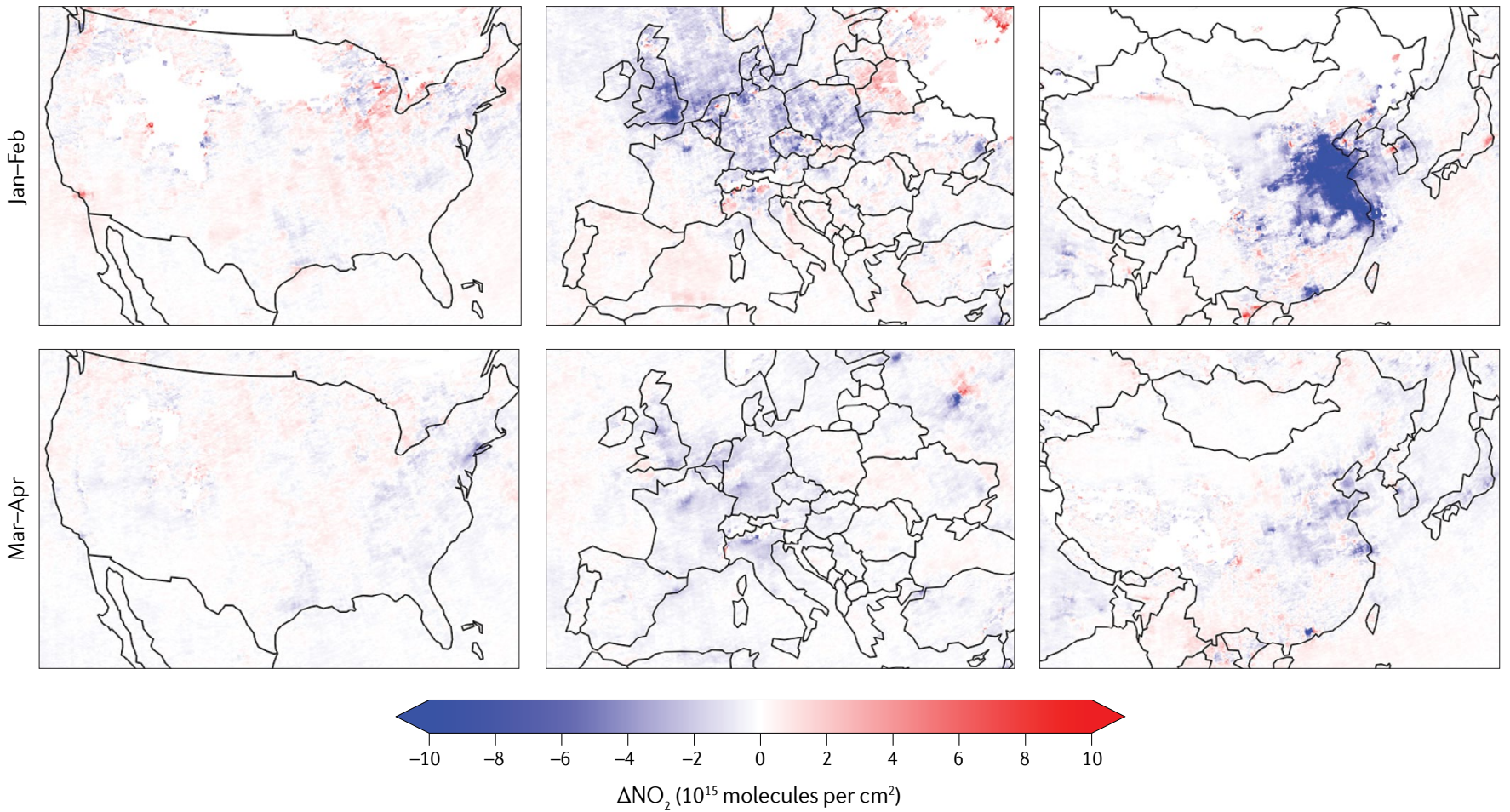

\section{b Aerosol optical depth}
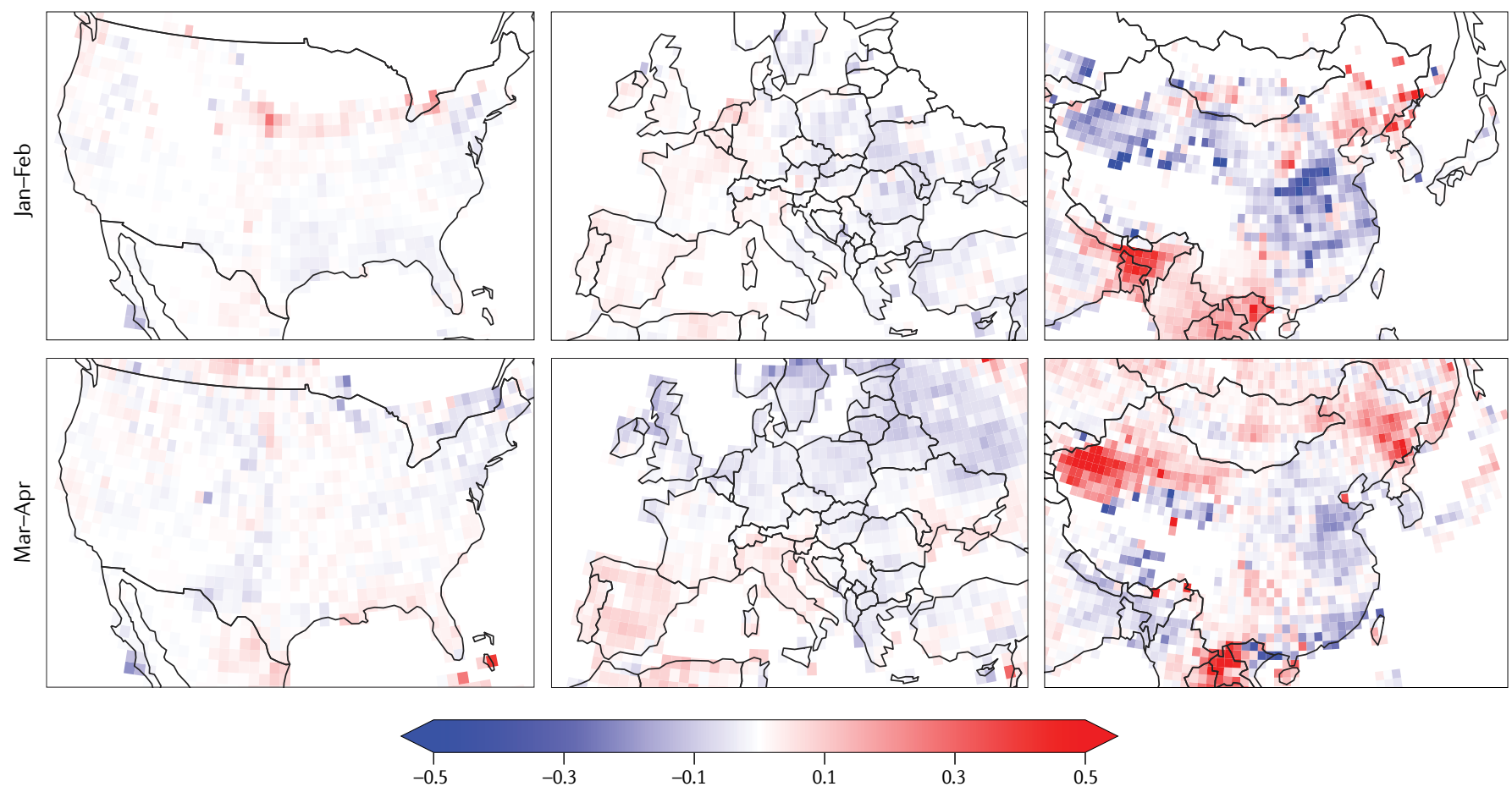

$-0.3$

$-0.1$

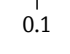

0.3

0.5

$\triangle \mathrm{AOD}$

Fig. 3 | Variability in air-quality indicators during the 2020 winterspring transition. Difference in tropospheric $\mathrm{NO}_{2}$ column density (panel a) and aerosol optical depth (panel b) for select months between 2020 and 2019. Aerosol optical depth (AOD) data are from the NASA Visible Infrared Imaging Radiometer Suite; $\mathrm{NO}_{2}$ data are from the NASA Ozone Monitoring Instrument, processed as in REF. ${ }^{94}$. Year-to-year changes in air quality reflect a complex array of processes in addition to COVID-19 restrictions.
For example, strong $\mathrm{NO}_{2}$ decreases over Northeast China coincide with the Wuhan lockdown ${ }^{95}$, while those over the UK in January-Febuary predate COVID-19 restrictions. Relative to $\mathrm{NO}_{2}$, AOD data show less regional coherency. Confident attribution to COVID-19 restrictions highlights a new challenge to explain these observed spatio-temporal differences and to place them in the context of the longer-term satellite and ground-based observations (BOX 2). 
expense of public transit. On the other hand, some cities might seek to maintain reductions in traffic by permanently closing some streets and encouraging residents to rely more on walking and bicycles. Another potentially consequential outcome could be a change in the kind of housing and work environments people will prefer in the future. The pandemic favours access to outdoor space and disfavours use of tall buildings with elevators. If these human preferences are sustained for years after the pandemic passes, over the long term, the combination could lead to more sprawling suburbs and fewer residential and office towers, with corresponding consequences for the Earth System.

More broadly, priorities and incentives embedded in government aid and economic stimulus will influence financial investment. For example, rollbacks of environmental restrictions by governments seeking to accelerate economic recovery ${ }^{33}$ (including fuel standards, mercury, clean water, and oil and gas production on federal lands) could have consequences that outlast the pandemic. Alternatively, efforts to support economic recovery could be directed towards electrification of transportation, along with green jobs that rebuild public transit, housing and critical infrastructure in an environmentally sensitive way ${ }^{18}$. In the private sector, pandemic-induced changes in perceptions of economic security and human needs could increase investment in technologies or platforms that lower the risk of future pandemics, such as reducing human interactions by introducing more robotics into workplaces. Although the precise trajectory is unknown, the long-term impacts of the pandemic on resource demand and efficiency will be heavily influenced by the response of human behaviour and decision-making, which is likely to vary among and within countries, as has occurred with health practices and policies during the pandemic.

\section{Investigative frameworks}

The COVID-19 sheltering has, thus far, been relatively brief, but its impacts are already emerging in the Earth System. Some of these responses, such as those directly connected to mobility and emissions of atmospheric pollutants, might pass when the sheltering passes (FIG. 2c, BOX 2), while others will persist long past the economic recovery (FIG. 1). Given the complexity of Earth System interactions, understanding these short-term, medium-term and long-term responses will require careful deployment of a diverse portfolio of investigative frameworks.
All traffic emissions removed

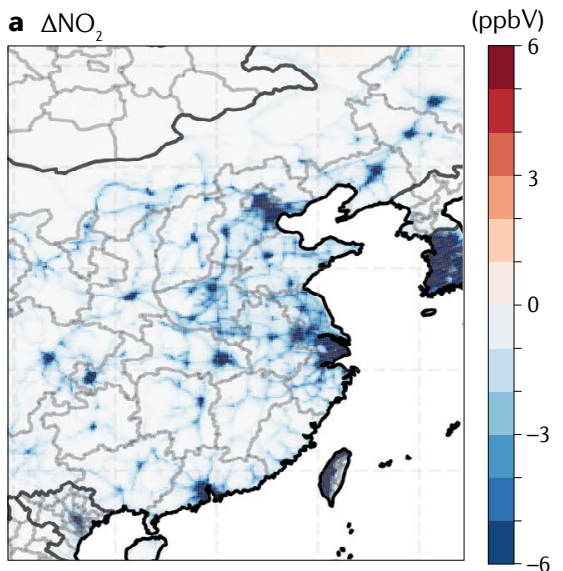

c $\triangle \mathrm{PM}_{2.5}$

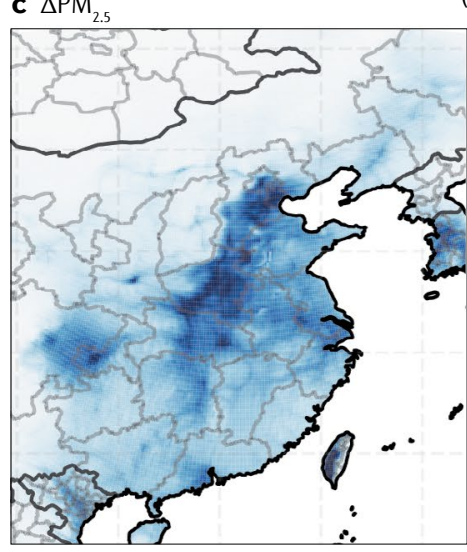

$\left(\mu \mathrm{g} \mathrm{m}^{-3}\right)$

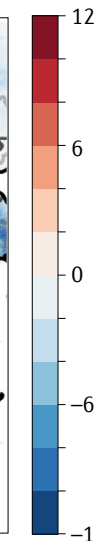

e $\Delta$ Surface temperature

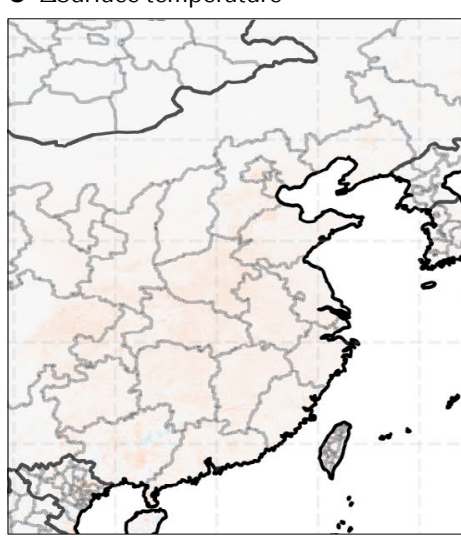

$\left({ }^{\circ} \mathrm{C}\right)$

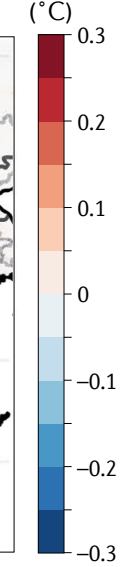

All power-plant emissions removed

b $\Delta \mathrm{SO}_{2}$

(ppbV)

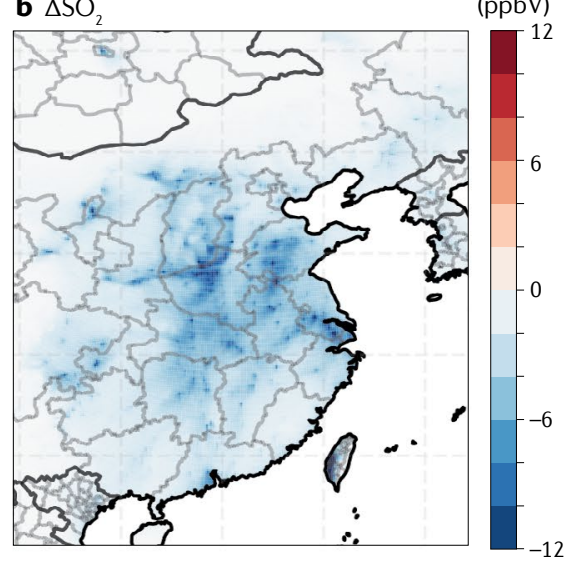

d $\triangle \mathrm{PM}_{2.5}$

$\left(\mu \mathrm{g} \mathrm{m}^{-3}\right)$

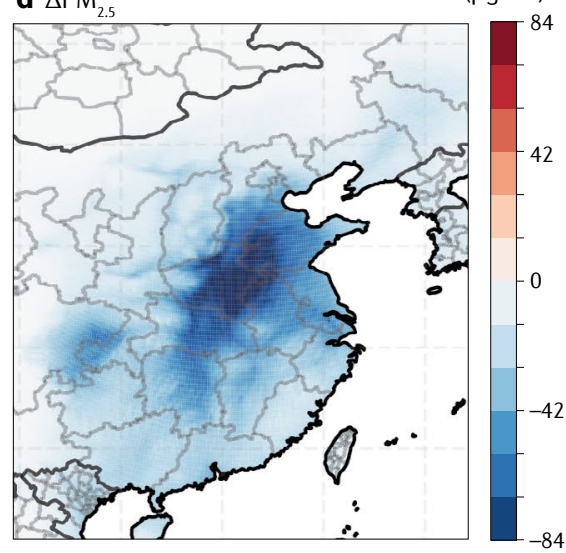

f $\Delta$ Surface temperature

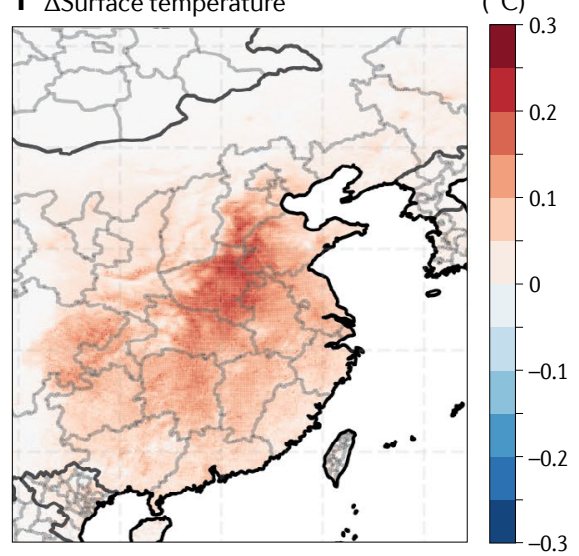

Fig. 4 | Idealized sensitivity to removal of emissions from traffic and power generation. $\mathrm{NO}_{2}$ (panel a), $\mathrm{SO}_{2}$ (panel $\mathbf{b}$ ), $\mathrm{PM}_{2.5}$ (panels $\mathbf{c}$ and $\mathbf{d}$ ) and surface-temperature (panels $\mathbf{e}$ and $\mathbf{f}$ ) changes for the month of January simulated by the Community Multiscale Air Quality/Weather Research and Forecasting (CMAQ-WRF) model in response to domain-wide removal of traffic (left panels) or power-plant (right panels) emissions. Experiments simulate one month using January 2010 emission factors and January 2013 meteorological fields. They are, thus, idealized illustrations of the potential for Earth System models to pose hypotheses, illuminate and constrain key processes, and identify data-gathering priorities; as these simulations predate the COVID-19 pandemic, they should not be considered an attempt to recreate COVID-19 conditions.

A major challenge will be to test causality when so many important, interacting influences are changing simultaneously. These include potentially confounding effects from large reductions in human activity, government interventions to stem the economic collapse, simultaneous market responses to both the economic 
shock and government stimulus, and underlying variations such as climate variability and pre-COVID-19 economic conditions. In addition, observational continuity is being affected by sheltering, including atmospheric, oceanic and land surface observations that contribute to the global observing system ${ }^{65}$. Given these challenges, insight must be generated from a combination of ongoing and newly deployed observations, dedicated modelling experiments, solutions-oriented randomized controlled trials (RCTs) and sophisticated quantitative analysis. To maximize effectiveness, these approaches will need to place as much focus on Path II (poverty, globalization, food and biodiversity) as on Path I (energy, emissions, climate and air quality). A key imperative will be to quickly develop and deploy techniques that can bring multiple lines of evidence together to distinguish causality.

\section{A new view to spatial and temporal dynamics of Earth System processes. Because} the timing of different government actions is $\mathrm{known}^{7}$, the spatio-temporal phasing of the socioeconomic disruption can be used to understand regional variations in the Earth System response. In essence, although interventions are occurring around the globe, we are not really experiencing a global shutdown but, rather, a complex patchwork of slowdowns in activity that vary widely in timing, duration, magnitude and baseline starting conditions (FIG. 2a). This variation is increasing as the event moves from the initial global disruption to heterogeneous resumption of activity (FIG. 2a) and extends across the seasonal transition from Northern Hemisphere winter to summer (and potentially beyond). Further, the scale of economic impacts suggest the possibility of sustained recession - or even depression - following the cessation of large-scale sheltering ${ }^{51,66}$. An extended period of substantially reduced economic activity would produce a trajectory of Earth System forcing that remains different from the pre-COVID-19 forcing, well after the COVID-19 restrictions are removed.

These spatial and temporal gradients in human activity are a source of information that becomes even more valuable in the context of observations that are repeated through time ${ }^{67}$ or that take advantage of the fact that variations in human interventions are at least partly independent of other co-varying, confounding factors ${ }^{68}$. The magnitude of the socioeconomic disruption is also large enough that it presents the opportunity to design data-gathering campaigns to systematically test hypotheses about both Path I and Path II that would not be observable without the disruption.

For example, the unprecedented reduction in daily fossil $\mathrm{CO}_{2}$ emissions (FIG. 2c) could lend insight into the processes governing land and ocean carbon sinks, provided that careful testing demonstrates that a signal can be detected amid the noise of natural variability, and that observations can be safely maintained during the event. Rapid declines in emissions can also help to narrow existing uncertainties around anthropogenic sources and their imprint on atmospheric trace gas and aerosol concentrations (BOX 2). Methane emissions from oil and gas fields offer one immediate example: so far during the event, oil and gas companies in the USA still maintained $\sim 11$ million barrels of daily crude oil production throughout the spring of 2020 , despite a $44 \%$ reduction in gasoline sales for the USA in April ${ }^{14}$. Not surprisingly, US inventories continue to climb, reaching their highest levels of the past four decades in June. If oil production slumps this summer, monitoring from satellites, aircraft, towers and on-the-ground sensors will provide an unprecedented opportunity to quantify any change in methane and ethane emissions, including decreases caused by lower production or increases caused by reduced oversight from workers or inspectors. But that will only be possible if the scientific community organizes and there is sufficient operational flexibility to allow for the collection of critical data.

A similar opportunity exists to study the effectiveness of wildfire suppression on air quality. In the USA, federal, state and local fire agencies are adjusting strategies in order to limit use of ground crews and their exposure to COVID-19 (REF. ${ }^{69}$ ). These strategies could influence aerosol loads from wildfires (which would have potential health consequences $^{70}$ ). It will, thus, be possible to systematically evaluate the effectiveness of this aggressive fire-suppression approach using existing satellite and ground-based observations.

Earth System models that predict responses
and guide observations. Computational
models are frequently used to test the
response of the Earth System to changes in
external forcing, including for quantifying
a counterfactual history without human
emissions and for generating climate
scenarios under future forcing from
greenhouse gases or solar geoengineering.
In recent decades, Earth System models
have become increasingly sophisticated and

complex, and have been shown to accurately reproduce $^{71}$, and predict ${ }^{72,73}$, many aspects of the Earth System ${ }^{6}$. However, limitations to validating the response to large changes in forcing have remained a persistent source of uncertainty, and the models still contain only rudimentary representations of the Path II impacts. The magnitude of the current socioeconomic disruption thus presents a unique setting for systematic Earth System model evaluation and development.

Earth System models could be deployed for a number of benefits. Because the magnitude of COVID-19 socioeconomic disruption is historically unprecedented, it will not be possible to identify all possible Earth System responses based on theory or historical experience alone. Earth System models could be used to create hypotheses that cannot be otherwise foreseen. Generating simulations early in the event - and leveraging pre-existing idealized experiments (FIG. 4) - could inform data collection and preservation, including any new observations that might be needed in order to validate unexpected modelling results (such as predictions of Path I and Path II impacts generated using existing empirical relationships ${ }^{74,75}$ ). After the event, when the temporal and spatial evolution of specific Earth System forcings is known, coordinated experiments ${ }^{76}$ would allow multiple Earth System models to be compared in a unified framework. The fact that the socioeconomic disruption is deliberately temporary will increase the ability to use data collected during and after the event to verify modelling results.

The event could also be used to evaluate the potential efficacy of specific policy interventions for both Path I and Path II impacts. For example, because atmospheric chemistry and pollutant accumulation in the near-surface environment are subject to variable meteorological conditions and highly nonlinear chemical interactions, consideration of policy interventions to improve air quality (such as incentives for electric-vehicle adoption) have relied heavily on theoretical arguments and model simulations. The scale of emissions reductions induced by the socioeconomic disruption opens an opportunity to use observations of primary and secondary pollutants to evaluate the performance of chemical-transport models in simulating a number of complex features of the event (FIG. 4).

For example, comparison of observations over northern China during the 2020 winter lockdown versus the same calendar 
period in 2019 shows higher ground-level ozone (as expected from theory and modelling, as NOx emissions decline in a high-NOx emission region ${ }^{77}$ ), which enhances atmospheric oxidizing capacity and subsequent formation of secondary aerosols, such as occurs in extreme-haze events ${ }^{22,78,79}$. In addition, sheltering policies have affected the emission-producing transportation, manufacturing and power-generation sectors ${ }^{12}$, though the degree and scope of shutdown in these individual sectors vary considerably ${ }^{13}$. Further, much of this change occurred against the backdrop of the transition from winter to spring, a period when insolation, water vapour and meteorology are changing rapidly. This transition was made even more complex this year by a large-scale dynamical pattern that resulted in a relatively cold spring over much of the central and eastern USA. Together, these challenges present a unique opportunity to evaluate Earth System model simulations of the air-quality response to emissions reductions in specific sectors (BOX 2).

In addition to implications for air quality, the representation of aerosol effects has been one of the key sources of uncertainties in Earth System models ${ }^{71,80,81}$. Should changes in regional aerosol concentrations occur as a result of the COVID-19 sheltering, the event could be used to verify simulated climatic consequences of policies to improve air quality, such as meteorological impacts like short-term increases in heat and precipitation extremes due to 'unmasking' of the effect of greenhouse gases ${ }^{82}$. A key concern is that these short-term, local signals (FIG. 4) need to be evaluated in the longer-term context of both internal climate variability and regulation-induced trends in aerosol emissions (BOX 2). However, the pervasiveness and persistence of the socioeconomic disruption may provide sufficient statistical power to test predictions generated by Earth System models.

\section{Solution-oriented interventions that create randomized research trials. Many} of the long-term impacts hypothesized in this Perspective will be determined by the response of human behaviour and decision-making. Systematically testing these human responses can be challenging. However, the scale of government response to the COVID-19 pandemic creates the opportunity to leverage solution-oriented interventions to create randomized research trials that can simultaneously provide assistance and insight about both Path I and Path II impacts.
Similar to the RCTs that are used to test the efficacy of vaccines and therapeutics, RCTs have been deployed to study a variety of other human outcomes, the effectiveness of which was recognized with this year's Nobel Prize in Economics. Although RCTs have been less frequently aimed at environmental outcomes, RCT feasibility has been demonstrated in a number of relevant contexts, including agricultural microcredit ${ }^{83}$ and payment for ecosystem services ${ }^{84-86}$. In addition, basic benchmarking studies have been conducted in single locations ${ }^{87}$. Together, these past studies provide the foundational research infrastructure that would be necessary to deploy RCT-based interventions in the COVID-19 context.

RCTs could be used to study vulnerability, resilience and disaster response in the face of extreme events that occur during sheltering ${ }^{88}$. Another prime candidate would be policy interventions designed to prevent the kind of long-term socio-environmental damage that becomes increasingly likely as the disruption becomes more severe and sustained ${ }^{51}$. For example, the emerging poverty shock ${ }^{50}$ can be expected to lead to substantial deforestation, land degradation and nutrient loss, even over the next few growing seasons, as smallholder farmers struggle to produce food with fewer inputs and households revert to harvested biomass for cooking. Similar socio-environmental cascades might occur in marine ecosystems. Solution-oriented RCTs would use random assignment (when the trial is of limited scale) or randomized phasing of participation (for comprehensive programmes) to test whether direct payments or other conditional mechanisms, such as payments for protection of ecosystem services, are effective in staving off environmental damages. Studies could compare the efficacy of a given treatment across different locations or domains, and could also benchmark generalized interventions (such as unconditional cash transfers) against more targeted solutions. In addition to helping vulnerable individuals and communities weather the COVID-19-driven poverty shock, such RCTs would provide a much deeper understanding of how and where poverty and environmental degradation are most tightly linked, and what types of interventions are doubly-protective of people and the environment.

A similar opportunity could exist in conjunction with COVID-19 relief and recovery funding. For example, if infrastructure spending is specifically included in recovery measures, that spending would provide an opportunity to systematically study the long-term effectiveness of green investments ${ }^{18}$ (including infrastructure and government programmes like jobs and conservation corps) in achieving Path I outcomes such as reduced greenhouse gas emissions and Path II outcomes such as increased resilience to climate extremes ${ }^{18,89}$. Even if federal or state stimulus measures do not explicitly include funding or requirements for these investments, the existing efforts of various states and localities to consider climate and other environmental outcomes in infrastructure investments ${ }^{89}$ would create an opening for well-designed, opportunistic research trials built around variations in how government stimulus funding is applied in the context of varying state and local jurisdictional constraints.

Voluntary, solution-oriented actions could create similar opportunities for both Path I and Path II impacts. For example, large fractions of residential developments in the western USA are at the wildlandurban interface. The lack of 'defensible space' around homes substantially increases wildfire risk. It has been proposed that residents who are able to shelter in place could allocate more effort to reducing their fire risk by increasing the defensible space around their homes ${ }^{90}$. With some foresight and investment, this effort could be used to study the effectiveness of defensible space. Other solution-oriented efforts that can be voluntarily undertaken while safely sheltering, such as local food production and preparation, could also be leveraged to study the effectiveness of adaptation and resilience interventions, as well as the effects of changes in consumption patterns on household carbon and environmental footprints.

\section{Summary and future perspectives}

The socioeconomic disruption associated with COVID-19 represents a highly unusual alteration of the human interaction with the Earth System. This alteration is likely to generate a series of responses, illuminating the processes connecting energy, emissions, air quality and climate, as well as globalization, food security, poverty and biodiversity (FIG. 1). In many cases, these long-term, indirect Earth System responses could be larger - and of opposite sign than the short-term environmental effects that have been immediately visible around the world. The potential for long-term impacts via Earth System cascades and feedbacks highlights the opportunity to use this period as an unintended experiment, 
and to use the knowledge gained to better predict, model and monitor Earth System processes during and after the event.

Given the uncertainty about the length of sheltering orders - and the nature of any interventions that may follow - it is impossible to know how long this inadvertent experiment will last. This uncertainty provides motivation for documenting hypotheses during this initial stage of the global crisis, so that data can be gathered and evaluated within the framework of a priori predictions, rather than post hoc analyses. Some hypotheses are only testable or conclusively verifiable by maintaining and/or deploying data collection during this early stage. Unless prohibited by safety concerns, it is important that these data continue to be collected so that the Earth System response to COVID-19 can be understood. By generating specific hypotheses based on initial observations, existing empirical relationships and process-based models, and then testing those hypotheses with existing and novel data sources, the COVID-19 socioeconomic disruption can provide novel insights into the processes that govern Earth System function and change.

Our primary motivation is to search for insight about the basic functioning of the Earth System that could be helpful in managing and recovering from the event, and in avoiding future impacts. Predicting the impacts of the sheltering on different components of the Earth System can help to aid in environment-related disaster preparedness in different regions. For example, analysis of the Earth System response can enable early detection of hotspots of environmental risk or degradation emerging during the event. Similarly, predicting, monitoring and understanding Earth System processes can help to support a sustainable economic, social and environmental recovery from the event. Although there is uncertainty about the length of the pandemic, the economic effects seem very likely to last for years. The individual, societal and government responses to these economic effects will influence the long-term trajectory of the human footprint on the Earth System.

The current socioeconomic disruption is a singular perturbation of that human footprint. Advancing understanding of this forcing, and the processes by which different components of the Earth System respond, can help to enhance robustness and resilience now and in the future.
Noah S. Diffenbaugh (iD ${ }^{1,2 \bowtie}$, Christopher B. Field (iD) ${ }^{1,2}$, Eric A. Appel (ID ${ }^{2,3}$, Ines L. Azevedo o,

Dennis D. Baldocchi ${ }^{5}$, Marshall Burke (iD ${ }^{1,2,6}$ Jennifer A. Burney $\mathbb{( D}^{7}$, Philippe Ciais (iD) ${ }^{8}$, Steven J. Davis (D) ${ }^{9}$, Arlene M. Fiore (D) ${ }^{10,11}$, Sarah M. Fletcher ${ }^{2,12}$, Thomas W. Hertel ${ }^{13}$, Daniel E. Horton ${ }^{14,15}$, Solomon M. Hsiang (iD ${ }^{16}$, Robert B. Jackson (iD ${ }^{1,2}$, Xiaomeng Jin (DD ${ }^{10}$, Margaret Levi'17,18, David B. Lobell( (D) 1,2,6, Galen A. McKinley (D) ${ }^{10,11}$, Frances C. Moore ${ }^{19}$, Anastasia Montgomery ${ }^{14}$, Kari C. Nadeau (iD) 2,20 , Diane E. Pataki ${ }^{21}$, James T. Randerson (ID), Markus Reichstein ${ }^{22}$, Jordan L. Schnell(DiD ${ }^{15,23,}$ Sonia I. Seneviratne (iD) ${ }^{24}$, Deepti Singh ${ }^{25}$, Allison L. Steiner ${ }^{26}$ and Gabrielle Wong-Parodi (iD ${ }^{1,2}$

'Department of Earth System Science, Stanford University, Stanford, CA, USA.

${ }^{2}$ Stanford Woods Institute for the Environment, Stanford University, Stanford, CA, USA.

${ }^{3}$ Department of Materials Science and Engineering, Stanford University, Stanford, CA, USA.

${ }^{4}$ Department of Energy Resources Engineering, Stanford University, Stanford, CA, USA.

${ }^{5}$ Department of Environmental Science, Policy, and Management, University of California, Berkeley, Berkeley, CA, USA.

${ }^{6}$ Center on Food Security and the Environment, Stanford University, Stanford, CA, USA.

${ }^{7}$ School of Global Policy \& Strategy, University of California, San Diego, La Jolla, CA, USA.

${ }^{8}$ Laboratoire des Sciences du Climat et de l'Environnement, Gif sur Yvette, France.

${ }^{9}$ Department of Earth System Science, University of California, Irvine, Irvine, CA, USA.

${ }^{10}$ Department of Earth \& Environmental Sciences, Columbia University, Palisades, New York, NY, USA.

"Lamont-Doherty Earth Observatory, Columbia University, Palisades, New York, NY, USA.

${ }^{12}$ Department of Civil and Environmental Engineering, Stanford University, Stanford, CA, USA.

${ }^{13}$ Department of Agricultural Economics, Purdue University, West Lafayette, IN, USA.

${ }^{14}$ Department of Earth and Planetary Sciences, Northwestern University, Evanston, IL, USA.

${ }^{15}$ Institute for Sustainability and Energy at Northwestern, Northwestern University, Evanston, IL, USA.

${ }^{16}$ Goldman School of Public Policy, University of California, Berkeley, Berkeley, CA, USA.

${ }^{17}$ Department of Political Science, Stanford University, Stanford, CA, USA.

${ }^{18}$ Center for Advanced Study in the Behavioral Sciences, Stanford University, Stanford, CA, USA.

${ }^{19}$ Department of Environmental Science and Policy, University of California, Davis, Davis, CA, USA.

${ }^{20}$ Division of Allergy, Immunology, \& Rheumatology, Stanford University, Stanford, CA, USA.

${ }^{21}$ School of Biological Sciences, University of Utah, Salt Lake City, UT, USA.

${ }^{22}$ Department of Biogeochemical Integration, Max Planck Institute for Biogeochemistry, Jena, Germany. ${ }^{23}$ Cooperative Institute for Research in Environmental Sciences, University of Colorado Boulder, Boulder, CO, USA.

${ }^{24}$ Institute for Atmospheric and Climate Science, ETH Zurich, Zürich, Switzerland.

${ }^{25}$ School of the Environment, Washington State University Vancouver, Vancouver, WA, USA.
${ }^{26}$ Department of Climate and Space Sciences and Engineering, University of Michigan, Ann Arbor, MI, USA.

凶e-mail: diffenbaugh@stanford.edu https://doi.org/10.1038/s43017-020-0079-1

Published online 29 July 2020

1. Soden, B. J., Wetherald, R. T., Stenchikov, G. L. \& Robock, A. Global cooling after the eruption of Mount Pinatubo: a test of climate feedback by water vapor. Science 296, 727-730 (2002).

2. Farquhar, G. D. \& Roderick, M. L. Pinatubo, diffuse light, and the carbon cycle. Science 299, 1997-1998 (2003).

3. Gu, L. H. et al. Response of a deciduous forest to the Mount Pinatubo eruption: enhanced photosynthesis. Science 299, 2035-2038 (2003).

4. Marufu, L. T. et al. The 2003 North American electrical blackout: an accidental experiment in atmospheric chemistry. Geophys. Res. Lett. 31, L13106 (2004).

5. Travis, D. J., Carleton, A. M. \& Lauritsen, R. G. Contrails reduce daily temperature range. Nature 418, 601 (2002)

6. Steffen, W. et al. The emergence and evolution of Earth System Science. Nat. Rev. Earth Environ. 1, 54-63 (2020).

7. Hale, T., Webster, S., Petherick, A., Phillips, T. \& Kira, B. Oxford COVID-19 Government Response Tracker https://covidtracker.bsg.ox.ac.uk (2020).

8. ILO. ILO Monitor: COVID-19 and the world of work. Fifth edition, 30June 2020. International Labour Organization https://www.ilo.org/wcmsp5/groups/ public/@dgreports/@dcomm/documents/briefingnote/ wcms_749399.pdf (2020).

9. Lenton, T. M. et al. Tipping elements in the Earth's climate system. Proc. Natl Acad. Sci. USA 105, 1786-1793 (2008).

10. Steffen, W. et al. Trajectories of the Earth System in the Anthropocene. Proc. Natl Acad. Sci. USA 115, 8252-8259 (2018).

11. Rockström, J. et al. Planetary boundaries: exploring the safe operating space for humanity. Ecol. Soc. 14, 32 (2009).

12. Liu, Z. et al. COVID-19 causes record decline in global $\mathrm{CO}_{2}$ emissions. Preprint at arXiv https://arxiv.org/ abs/2004.13614v3 (2020).

13. Le Quéré, $C$. et al. Temporary reduction in daily global $\mathrm{CO}_{2}$ emissions during the COVID-19 forced confinement. Nat. Clim. Change 10, 647-653 (2020).

14. EIA. Short-Term Energy Outlook (STEO). July 2020. U.S. Energy Information Administration https://www. eia.gov/outlooks/steo/pdf/steo_full.pdf (2020).

15. Jackson, R. B. et al. Global energy growth is outpacing decarbonization. Environ. Res. Lett. 13, 120401 (2018).

16. Peters, G. P. et al. Rapid growth in $\mathrm{CO}_{2}$ emissions after the 2008-2009 global financial crisis. Nat. Clim. Change 2, 2-4 (2012).

17. Feng, K., Davis, S. J., Sun, L. \& Hubacek, K. Drivers of the US $\mathrm{CO}_{2}$ emissions 1997-2013. Nat. Commun. 6 7714 (2015).

18. Hanna, R., Xu, Y. \& Victor, D. G. After COVID-19, green investment must deliver jobs to get political traction. Nature 582, 178-180 (2020).

19. Zheng, B. et al. Satellite-based estimates of decline and rebound in China's $\mathrm{CO}_{2}$ emissions during COVID-19 pandemic. Preprint at arXiv https://arxiv. org/abs/2006.08196v1 (2020).

20. Friedlingstein, P. et al. Global carbon budget 2019. Earth Syst. Sci. Data 11, 1783-1838 (2019).

21. McKinley, G. A., Fay, A. R., Eddebbar, Y. A., Gloege, L. $\&$ Lovenduski, N. S. External forcing explains recent decadal variability of the ocean carbon sink. $A G U A d v$. https://doi.org/10.1029/2019AV000149 (2020).

22. Le, T. et al. Unexpected air pollution with marked emission reductions during the COVID-19 outbreak in China. Science https://doi.org/10.1126/science. abb7431 (2020).

23. Ramanathan, V., Crutzen, P. J., Kiehl, J. T. \& Rosenfeld, D. Aerosols, climate, and the hydrological cycle. Science 294, 2119-2124 (2001).

24. Rosenfeld, D. et al. Flood or drought: how do aerosols affect precipitation? Science 321, 1309-1313 (2008)

25. Wild, M. Global dimming and brightening: a review. J. Geophys. Res. Atmos. 114, D00D16 (2009).

26. Westervelt, D. M. et al. Local and remote mean and extreme temperature response to regional aerosol emissions reductions. Atmos. Chem. Phys. 20 3009-3027 (2020). 
27. Mickley, L. J., Leibensperger, E. M., Jacob, D. J. \& Rind, D. Regional warming from aerosol removal over the United States: results from a transient 2010-2050 climate simulation. Atmos. Environ 46, 545-553 (2012).

28. Mascioli, N. R., Fiore, A. M., Previdi, M. \& Correa, C. Temperature and precipitation extremes in the United States: quantifying the responses to anthropogenic aerosols and greenhouse gases. J. Clim. 29, 2689-2701 (2016)

29. Bollasina, M. A., Ming, Y. \& Ramaswamy, V. Anthropogenic aerosols and the weakening of the South Asian summer monsoon. Science 334, 502-505 (2011)

30. Lin, L., Wang, Z., Xu, Y., Fu, Q. \& Dong, W. Larger sensitivity of precipitation extremes to aerosol than greenhouse gas forcing in CMIP5 models. J. Geophys. Res. Atmos. 123, 8062-8073 (2018).

31. Singh, D., Bollasina, M., Ting, M. \& Diffenbaugh, N. S. Disentangling the influence of local and remote anthropogenic aerosols on South Asian monsoon daily rainfall characteristics. Clim. Dyn. 52, 6301-6320 (2019).

32. EIA. Annual Energy Outlook 2020. U.S. Energy Information Administration https://www.eia.gov/ outlooks/aeo/pdf/AEO2020 Full Report.pdf (2020).

33. Bodine, S. P. COVID-19 Implications for EPA's Enforcement and Compliance Assurance Program. United States Environmental Protection Agency https://www.epa.gov/sites/production/files/2020-03/ documents/oecamemooncovid 19 implications.pdf (2020).

34. Burney, J. \& Ramanathan, V. Recent climate and air pollution impacts on Indian agriculture. Proc. Natl Acad. Sci. USA 111, 16319-16324 (2014).

35. Avnery, S., Mauzerall, D. L., Liu, J. \& Horowitz, L. W. Global crop yield reductions due to surface ozone exposure: 2. Year 2030 potential crop production losses and economic damage under two scenarios of $\mathrm{O}_{3}$ pollution. Atmos. Environ. 45, 2297-2309 (2011).

36. Cohen, A. J. et al. Estimates and 25-year trends of the global burden of disease attributable to ambient air pollution: an analysis of data from the Global Burden of Diseases Study 2015. Lancet 389, 1907-1918 (2017).

37. Liu, C. et al. Ambient particulate air pollution and daily mortality in 652 cities. N. Engl. J. Med. 381 705-715 (2019)

38. WHO. Ambient air pollution: A global assessment of exposure and burden of disease. World Health Organization https://apps.who.int/iris/bitstream/hand le/10665/250141/9789241511353-eng.pdf (2016).

39. Schraufnagel, D. E. et al. Health benefits of air pollution reduction. Ann. Am. Thorac. Soc. 16, 1478-1487 (2019).

40. Friedman, M. S., Powell, K. E., Hutwagner, L., Graham, L. M. \& Teague, W. G. Impact of changes in transportation and commuting behaviors during the 1996 Summer Olympic Games in Atlanta on air quality and childhood asthma. JAMA 285, 897-905 (2001).

41. Li, Y., Wang, W., Kan, H., Xu, X. \& Chen, B. Air quality and outpatient visits for asthma in adults during the 2008 Summer Olympic Games in Beijing. Sci. Total Environ. 408, 1226-1227 (2010).

42. Wang, S. et al. Quantifying the air pollutants emission reduction during the 2008 Olympic Games in Beijing. Environ. Sci. Technol. 44, 2490-2496 (2010).

43. Su, C. et al. Assessing responses of cardiovascular mortality to particulate matter air pollution for pre-, during- and post-2008 Olympics periods. Environ. Res. 142, 112-122 (2015).

44. He, G., Fan, M. \& Zhou, M. The effect of air pollution on mortality in China: Evidence from the 2008 Beijing Olympic Games. J. Environ. Econ. Manage. 79, 18-39 (2016).

45. Rich, D. Q. et al. Association between changes in air pollution levels during the Beijing Olympics and biomarkers of inflammation and thrombosis in healthy young adults. JAMA 307, 2068-2078 (2012).

46. Wu, X., Nethery, R. C., Sabath, B. M., Braun, D. \& Dominici, F. Exposure to air pollution and COVID-19 mortality in the United States: a nationwide crosssectional study. Preprint at medRxiv https://www. medrxiv.org/content/10.1101/2020.04.05. 20054502v2 (2020)

47. Liang, D. et al. Urban air pollution may enhance COVID-19 case-fatality and mortality rates in the United States. Preprint at medRxiv https://www. medrxiv.org/content/10.1101/2020.05.04 20090746v1 (2020).
48. Burke, M., Davis, W. M. \& Diffenbaugh, N. S. Large potential reduction in economic damages under UN mitigation targets. Nature 557, 549-553 (2018).

49. Moore, F. C. \& Diaz, D. B. Temperature impacts on economic growth warrant stringent mitigation policy. Nat. Clim. Change 5, 127-131 (2015).

50. UNDESA. World Economic Situation and Prospects as of mid-2020. United Nations https://www.un.org/ development/desa/dpad/wp-content/uploads/sites/45/ publication/WESP2020_MYU_Report.pdf (2020).

51. Guan, D. et al. Global economic footprint of the COVID-19 pandemic. Nat. Hum. Behav. 4, 577-587 (2020).

52. Lusk, J. Ruminations on solutions to the COVID-related food disruptions. Jayson Lusk http://jaysonlusk.com/ blog/2020/5/12/ruminations-on-solutions-to-the-covidrelated-food-disruptions (2020)

53. WTO. Methodology for the WTO trade forecast of April 8 2020. World Trade Organization https://www. wto.org/english/news_e/pres20_e/methodpr855_e.pdf (2020).

54. Martin, W. \& Anderson, K. Export restrictions and price insulation during commodity price booms Policy Research Working Paper no. WPS 5645. World Bank Group http://documents.worldbank.org/curated/ en/583201468337175309/Export-restrictions-andprice-insulation-during-commodity-price-booms (2011).

55. Battisti, D. S. \& Naylor, R. L. Historical warnings of future food insecurity with unprecedented seasonal heat. Science 323, 240-244 (2009)

56. Laborde, D., Mamun, A. \& Parent, M. COVID-19 Food Trade Policy Tracker. International Food Policy Research Institute https://www.ifpri.org/project/ covid-19-food-trade-policy-tracker (2020).

57. Diao, X. \& Kennedy, A. Economywide impact of maize export bans on agricultural growth and household welfare in Tanzania: a dynamic computable general equilibrium model analysis. Dev. Policy Rev. 34, 101-134 (2016)

58. Anderson, K. \& Nelgen, S. Agricultural trade distortions during the global financial crisis. Oxf. Rev. Econ. Policy 28, 235-260 (2012).

59. Ahmed, S. A., Diffenbaugh, N. S., Hertel, T. W. \& Martin, W. J. Agriculture and trade opportunities for Tanzania: past volatility and future climate change. Rev. Dev. Econ. 16, 429-447 (2012).

60. Roth, A. Poachers kill more rhinos as coronavirus halts tourism to Africa. New York Times (8 Apr 2020) https://www.nytimes.com/2020/04/08/science/ coronavirus-poaching-rhinos.html (2020).

61. INPE. Earth observation general coordination. Monitoring program of the Amazon and other biomes. Deforestation - legal Amazon. National Institute for Space Research http://terrabrasilis.dpi.inpe.br/app/ dashboard/alerts/legal/amazon/aggregated/ (2020).

62. Barrett, C. B., Travis, A. J. \& Dasgupta, P. On biodiversity conservation and poverty traps. Proc. Natl Acad. Sci. USA 108, 13907-13912 (2011).

63. Oldekop, J. A., Sims, K. R. E., Karna, B. K Whittingham, M. J. \& Agrawal, A. Reductions in deforestation and poverty from decentralized forest management in Nepal. Nat. Sustain. 2, 421-428 (2019).

64. Rutz, C. et al. COVID-19 lockdown allows researchers to quantify the effects of human activity on wildlife. Nat. Ecol. Evol https://doi.org/10.1038/s41559020-1237-z (2020).

65. WMO COVID-19 impacts observing system. World Meteorological Organization https://public.wmo.int en/media/press-release/covid-19-impacts-observingsystem (2020)

66. Baker, S. R., Bloom, N., Davis, S. J. \& Terry, S. J. COVID-induced economic uncertainty. NBER Working Paper No. 26983. National Bureau of Economic Research http://www.nber.org/papers/w26983.pdf (2020).

67. Runge, J. et al. Inferring causation from time series in Earth system sciences. Nat Commun. 10, 2553 (2019).

68. Peters, J., Janzing, D. \& Schölkopf, B. Elements of Causal Inference: Foundations and Learning Algorithms 288 pp (MIT Press, 2017).

69. Murkowski, L. April 2, 2020, Letter to Secretary Barnhardt and Secretary Perdue. U.S. Senate Committee on Energy \& Natural Resources https:// www.energy.senate.gov/public/index.cfm?a=files. serve\&File_id=988D2496-CB4C-4D63-8213EE5F0DD30CA0 (2020)

70. Prunicki, M. et al. The impact of prescribed fire versus wildfire on the immune and cardiovascular systems of children. Allergy 74, 1989-1991 (2019).

71. Flato, G. et al. in Climate Change 2013: The Physical Science Basis. Contribution of Working Group I to the
Fifth Assessment Report of the Intergovernmental Panel on Climate Change (eds Stocker, T. F. et al.) 741-866 (Cambridge Univ. Press, 2013).

72. Hausfather, Z., Drake, H. F., Abbott, T. \& Schmidt, G. A Evaluating the performance of past climate model projections. Geophys. Res. Lett. 47, e2019GL085378 (2020).

73. Diffenbaugh, N. S. Verification of extreme event attribution: using out-of-sample observations to assess changes in probabilities of unprecedented events. Sci. Adv. 6, eaay2368 (2020).

74. Heft-Neal, S., Lobell, D. B. \& Burke, M. Using remotely sensed temperature to estimate climate response functions. Environ. Res. Lett. 12, 14013 (2017).

75. Carleton, T. A. \& Hsiang, S. M. Social and economic impacts of climate. Science 353, aad9837 (2016).

76. Eyring, V. et al. Overview of the Coupled Model Intercomparison Project Phase 6 (CMIP6) experimental design and organization. Geosci. Model. Dev. 9 1937-1958 (2016).

77. Sillman, S., Logan, J. A. \& Wofsy, S. C. The sensitivity of ozone to nitrogen oxides and hydrocarbons in regional ozone episodes. J. Geophys. Res. Atmos. 95, 1837-1851 (1990).

78. Huang, X. et al. Enhanced secondary pollution offset reduction of primary emissions during COVID-19 lockdown in China. Natl. Sci. Rev. https://doi.org/ 10.1093/nsr/nwaa137 (2020).

79. Shi, X. \& Brasseur, G. P. The response in air quality to the reduction of Chinese economic activities during the COVID-19 outbreak. Geophys. Res. Lett. 47, e2020GL088070 (2020).

80. Storelvmo, T. et al. Lethargic response to aerosol emissions in current climate models. Geophys. Res. Lett. 45, 9814-9823 (2018)

81. Bellouin, N. et al. Bounding global aerosol radiative forcing of climate change. Rev. Geophys. $\mathbf{5 8}$ e2019RG000660 (2020).

82. Samset, B. H. et al. Climate impacts from a removal of anthropogenic aerosol emissions. Geophys. Res. Lett. 45, 1020-1029 (2018).

83. Burke, M., Bergquist, L. F. \& Miguel, E. Sell low and buy high: arbitrage and local price effects in Kenyan markets. Q. J. Econ. 134, 785-842 (2018).

84. Alix-Garcia, J. M. et al. Payments for environmenta services supported social capital while increasing land management. Proc. Natl Acad. Sci. USA 115. 7016-7021 (2018).

85. Alix-Garcia, J. M., Sims, K. R. E. \& Yañez-Pagans, P. Only one tree from each seed? Environmental effectiveness and poverty alleviation in Mexico's Payments for Ecosystem Services Program. Am. Econ. J. Econ. Policy 7, 1-40 (2015).

86. Jayachandran, S. et al. Cash for carbon: a randomized trial of payments for ecosystem services to reduce deforestation. Science 357, 267-273 (2017).

87. GiveDirectly. Research at GiveDirectly. GiveDirectly https://www.givedirectly.org/research-at-give-directly/ (2020).

88. Phillips, C. A. et al. Compound climate risks in the COVID-19 pandemic. Nat. Clim. Change 10, 586-588 (2020).

89. Climate-Safe Infrastructure Working Group (CSIWG). Paying it Forward: The Path Toward Climate-Safe Infrastructure in California. State of California https:// www.adaptationclearinghouse.org/resources/payingit-forward-the-path-toward-climate-safe-infrastructurein-california html (2018).

90. Field, C. B. \& Appel, E. A. Will the pandemic make the West more vulnerable to wildfires? New York Times (15 May 2020) https://www.nytimes.com/2020/05/14 opinion/wildfires-coronavirus.html (2020).

91. SafeGraph. U.S. Geographic Responses to Shelter in Place Orders: Percent Staying Home. SafeGraph https://www.safegraph.com/dashboard/covid19shelter-in-place (2020).

92. Le Quéré, C. et al. Supplementary data to: Le Quéré et al (2020), Temporary reduction in daily global $\mathrm{CO}_{2}$ emissions during the COVID-19 forced confinement (Version 1.0). Global Carbon Project. Integrated Carbon Observation System https://www.icos-cp.eu/ gcp-covid 19 (2020).

93. Liu, Z. et al. Carbon Monitor: a near-real-time daily dataset of global $\mathrm{CO}_{2}$ emission from fossil fuel and cement production. Preprint at arXiv https://arxiv.org/ abs/2006.07690v1 (2020).

94. Jin, X., Fiore, A., Boersma, K. F., De Smedt, I. \& Valin, L. Inferring changes in summertime surface ozone- $\mathrm{NO}_{x}-\mathrm{VOC}$ chemistry over U.S. urban areas from two decades of satellite and ground-based observations. Environ. Sci. Technol. 54, 6518-6529 (2020). 
95. Bauwens, M. et al. Impact of coronavirus outbreak on $\mathrm{NO}_{2}$ pollution assessed using TROPOM and OMI observations. Geophys. Res. Lett. 47, e2020GL087978 (2020).

96. Hawkins, E. \& Sutton, R. The potential to narrow uncertainty in regional climate predictions. Bull. Am. Meteorol. Soc. 90, 1095-1107 (2009).

97. Deser, C., Knutti, R., Solomon, S. \& Phillips, A. S. Communication of the role of natural variability in future North American climate. Nat. Clim. Change 2 775-779 (2012).

98. Horton, D. E et al Contribution of changes in atmospheric circulation patterns to extreme temperature trends. Nature 522, 465-469 (2015).

\section{Acknowledgements}

This article grew from discussions initiated in the Uncommon Dialogue programme of the Stanford Woods Institute for the Environment. The authors acknowledge support from Stanford University. K.C.N. acknowledges financial support from NIEHS R01 and Sean N. Parker Center at Stanford. G.A.M. acknowledges support from NSF OCE-1948624. T.W.H. acknowledges support from USDA-NIFA 2019-67023 29679 and Hatch 1003642 . D.E.H., A.M. and J.L.S acknowledge support from the Ubben Program for Climate and Carbon Science at the Institute for Sustainability and Energy at Northwestern. P.C. acknoweldges support from the European Research Council Synergy grant SyG-2013 610028 IMBALANCE-P and the ANR CLAND Convergence Institute.

\section{Author contributions}

All authors made substantial contributions to discussion of content and review/editing of the manuscript. N.S.D., C.B.F. J.A.B., A.M.F., T.W.H., D.E.H., F.C.M., K.C.N., M.R. and A.L.S contributed the initial writing. N.S.D., C.B.F., D.D.B., M.B.,
P.C., S.J.D., A.M.F., D.E.H., R.B.J., X.J., A.M. and J.L.S researched data for the article. N.S.D. and C.B.F. convened the group and coordinated the drafting and revisions of the figures and manuscript. N.S.D. assembled the initial draft.

\section{Competing interests}

The authors declare no competing interests.

\section{Peer review information}

Nature Reviews Earth \& Environment thanks the anonymous reviewer(s) for their contribution to the peer review of this work.

\section{Publisher's note}

Springer Nature remains neutral with regard to jurisdictional claims in published maps and institutional affiliations.

(C) Springer Nature Limited 2020 